\title{
Las razones del éxito de PODEMOS: populismo, comunicación audiovisual y marketing político*
}

\author{
José Ismael Criado Aguilera** \\ Recibido: 2016-07-28 Enviado a pares: 2016-08-10 \\ Aprobado por pares: 2016-10-06 Aceptado: 2016-11-11 \\ DOI: 10.22395/angr.v15n30a3
}

\begin{abstract}
Resumen
Este trabajo comienza describiendo la profunda crisis socio-económica y política que se sufre en España, donde se manifiesta cada vez con mayor intensidad la descomposición de los pilares maestros que sustentan el régimen político actual (entre otros, la monarquía, el consenso entre las élites, el bipartidismo y el Estado social). La ofensiva neoliberal que ha empobrecido sistemáticamente a las clases trabajadoras del mundo tuvo en nuestro país un punto de ruptura social explosivamente manifestado en el movimiento del 15 de mayo de 2011 (15M), lo cual evidenció una profunda crisis de legitimidad y representatividad a la cual Podemos, el partido político liderado por Pablo Iglesias, ha sabido dar respuesta mediante la construcción y comunicación de un discurso participativo y radicalmente democrático. Esta estrategia de batallar la hegemonía, tomada de teóricos políticos como Gramsci y Laclau, se ha aplicado en el diseño de una nueva forma de liderazgo y la articulación de una estrategia mediática adecuada a la realidad concreta del país, una democracia mediática donde priman la desconfianza y la apatía ciudadana hacia la política.
\end{abstract}

La configuración del discurso con base en conceptos como casta, pueblo, crisis de régimen o proceso constituyente ha tenido una gran acogida en la sociedad, y ello se demuestra crecientemente en las sucesivas elecciones, donde observamos un derrumbe del bipartidismo y una expectativa de cambio radical en el sistema político español; la soberanía popular, la democracia y el futuro de los pueblos de España están en juego, y Podemos promete ser el jugador que decida el rumbo de la partida.

Palabras clave: democracia, discurso político, populismo, comunicación política, marketing político.

Artículo de investigación patrocinado por la Universidad de Granada (España). Proyecto de investigación Las razones del éxito de PODEMOS Departamento de Ciencia Política y de la Administración. Financiado por el Programa Formación del Profesorado Universitario(FPU) del Ministerio de Educación, Cultura y Deporte (Gobierno de España). ESPAÑA.

** Investigador FPU en Comunicación y Teoría Política del Departamento de Ciencia Política de la Universidad de Granada. Graduado en Ciencias Políticas y de la Administración (UGR). Máster Universitario en Derecho Constitucional (Centro de Estudios Políticos y Constitucionales \& Universidad Internacional Menéndez Pelayo). Premio Andaluz a la mejor trayectoria académica en Ciencias Políticas (Acsyma \& Unicaja, 2016). Premio a la Excelencia en el rendimiento académico (UGR \& Caja Rural de Granada, 2015).criadoaguilera@correo.ugr.es 


\title{
The reasons for the success of podemos: populism, audiovisual communication and political marketing
}

\begin{abstract}
This work begins describing the deep, wide socio-economic and political crisis that Spain is going through, a country in which the downfall of the pillars on which the inherited franquist regime is sustained (monarchy, elite consensus, bipartidism and the social State) is clearer every day. The neoliberal offensive, which has systematically plunged the working classes around the world into poverty, had an explosive social rupture point in our country expressed in the 15 May of 2011 movement $(15 \mathrm{M})$, which evidenced a deep crisis of legitimacy and representativity, to which Podemos, the party led by Pablo Iglesias, has managed to give an answer through the construction and communication of a participative, radically democratic discourse in order to fight for conquering the hegemony, referred to political theorists as Gramsci and Laclau. This has been used to build a new way of leadership and the articulation of a media strategy coherent to the reality of the country, dominated by mass media as powerful, decisive actors of the political process, while the citizenship is featured to be apathetic and unconfident about the Politic. The discourse configuration, based on concepts such as caste, people, regime crisis and constitutive process, has had a great reception in the society, and that was confirmed more a more in the elections, at which we could witness the collapse of the bipartidist system and a radical change of expectations in the Spanish political system; popular sovereignty, democracy and the Spanish people's future are in play, and Podemos promises to be the player who is going to decide the game direction.
\end{abstract}

Key words: democracy, political discourse, populism, political communication, political marketing.

\section{As razões para o sucesso da podemos: o populismo, a comunicação audiovisual e marketing político}

\begin{abstract}
Resumo
Este artigo começa por descrever a profunda crise socioeconômica e política que sofre na Espanha, que se manifesta com o aumento da intensidade da decomposição professores pilares de sustentação do regime político atual (entre outros, a monarquia, o consenso entre as elites, bipartidarismo e o estado de bem-estar). A ofensiva neoliberal tem sistematicamente empobrecidas as classes trabalhadoras do mundo teve em nosso país uma ruptura social, explosivamente manifesta no movimento de 15 de maio de 2011 (15M), que mostrou uma profunda crise de legitimidade e representação a que nós, o partido político liderado por Pablo Iglesias, tem sido capaz de responder através da construção e comunicar um discurso radicalmente participativa e democrática. Essa hegemonia estratégia de batalha, tomada de teóricos políticos como Gramsci e Laclau, tem sido aplicada no desenho de uma nova forma de liderança e articulação de uma estratégia de mídia adequada à realidade concreta do país, uma democracia de mídia era passada de desconfiança e apatia dos cidadãos em relação à política. A configuração do discurso baseado em conceitos como casta, vila, regime de crise ou processo constitucional tem sido muito bem recebido na sociedade, e isso é cada vez mais demonstrado nas eleições sucessivas, onde vemos um colapso do bipartidarismo e uma expectativa de mudança radical no sistema político espanhol; soberania popular, a democracia e o futuro do povo da Espanha estão em jogo e promete ser o jogador pode decidir o rumo do jogo.
\end{abstract}

Palavras chave: democracia, discurso político, populismo, comunicação política, marketing político. 


\section{Introducción}

\section{Situación socio-política y económica de España ante las elecciones europeas}

En este primer apartado se analizan los principales rasgos socio-económicos de nuestro país, donde encontramos que la cultura política y mediática de la sociedad española es un campo abonado para el empleo fructífero de herramientas del discurso populista, con su inherente efecto rompedor, teniendo en cuenta la desconfianza y pérdida de legitimidad del régimen democrático-liberal fundado con la Constitución de 1978.

Partimos de una realidad socio-económica y política compleja y cambiante; inserta en los procesos mundiales de globalización y de crisis del sistema capitalista internacional, la sociedad española atraviesa, además, una crisis propia, autóctona, que desde algunos grupos y movimientos socio-políticos como la formación Podemos ( $3^{a}$ fuerza política en las últimas elecciones generales) se ha denominado "Crisis de régimen"; El debilitamiento de las principales fuentes legitimadoras de este (monarquía, bipartidismo, consenso entre las élites, concertación social, Estado del Bienestar...) demuestra el fuerte descrédito del sistema democrático actual fundado con la Constitución de 1978 sufrido en los últimos años, sobre lo cual, aun sin poder constatar su irreversibilidad o no, podemos pronosticar el advenimiento de grandes cambios en el sistema político español para los próximos años.

En general en las sociedades occidentales desarrolladas, y obviamente en España, observamos que fenómenos como la desactivación de los cleavages ideológicos y el aumento de la volatilidad electoral, los mínimos índices de militancia política y las nuevas formas de participación política han puesto a los medios de comunicación tradicionales y modernos en el centro de las estrategias de campaña. Concretamente en nuestro país partimos también de la concepción de que la cultura política latina / hispana se caracteriza por ser raramente consensual; al contrario, vivimos en una realidad socio-política polarizada, pluralista-competitiva, históricamente autoritaria, personalista, con un fuerte componente anárquico y explosivo en su manifestación, donde triunfan los liderazgos fuertes, carismáticos.

Con el presente estudio abordamos un fenómeno que en muy poco tiempo ha logrado romper muchos de los esquemas del sistema político español. El amplio apoyo social que ha recibido, así como la transversalidad de este, han sido algunas de las claves de su éxito, siendo capaz de movilizar y atraer la participación de sectores muy diversos y capas de la sociedad hasta entonces instrumentalizadas, ignoradas y que sistemática o progresivamente se habían alejado de todo lo relacionado con política por considerarla problemática o simplemente inútil (anti-política).

Mediante una estrategia tan eficiente como eficaz, Podemos llega cada vez más a rincones inaccesibles de la heterogénea sociedad española aprovechando con tremenda inteligencia política el potente entramado mediático hilvanado por las grandes corporaciones de la comunicación que operan en nuestro país, así como el frenético crecimiento de las redes sociales de Internet, instrumentos que han servido a Podemos como trampolín 
para saltar a los escenarios políticos de masas (no solo para la difusión de su discurso, sino también para hacer partícipes a decenas de miles de personas con su proyecto político participativo, abierto y horizontal).

\section{Del 15m de 2011 al 25m de 2014: nuevas formas de hacer política}

Las nuevas formas de protesta y movilización ciudadana, surgidas como un maremoto a principios del siglo XXI, se dirigen contra el poder omnímodo de las empresas y las evasiones fiscales sistemáticas del 1 \% más rico de la población, y están inspiradas en las protestas en España de 2011 que surgieron con el Movimiento 15-M, recorriendo el mundo de Méjico a Wall Street, de Hong Kong a Tokio, del Magreb a Australia. En nuestro país, PODEMOS ha sabido emerger como actor político determinante articulando un discurso canalizador del descontento y la desesperación social mayoritaria.

Los efectos de las movilizaciones masivas y acampadas del 15M significaron una interrupción de la dinámica social hegemónica de las creencias políticas surgidas en los momentos de su constitución, dando inicio a una nueva construcción de creencias que compiten por el espacio, el poder y el convencimiento del pueblo, que no tenían como protagonistas a los partidos históricos tradicionales.

Desde las luchas comunes contra la globalización neoliberal y sus devastadores efectos se ha construido una historia y un trabajo común que permitió algunos avances, particularmente en América Latina (Bolivia, Ecuador, o Argentina...) donde lograron frenar alianzas neoliberales y concretar alternativas populares para un desarrollo socialmente justo y respetuoso de la vida mediante un crecimiento cuantitativo y cualitativo de los movimientos sociales, su organización y acción.

Es este el punto de partida adecuado para el surgimiento y el éxito de un discurso político alternativo como el de Podemos, que aúna inteligentemente unas dinámicas de funcionamiento radicalmente opuestas a las formas de actuar y de pensar que se critican (como el neoliberalismo, la corrupción, opacidad...) y una operatividad interna y externa muy eficaz, basada en la buena estructuración de los significantes comunes, combinada con las buenas dotes de liderazgo y comunicación política de sus principales promotores (Iglesias, Monedero, Errejón...) en la difusión de su discurso.

\section{Discurso político de Podemos en campaña electoral}

El análisis crítico de las relaciones entre estructuras y estrategias del discurso, la interacción y las relaciones de la sociedad habilita el análisis del discurso a hacer aportes sensatos al estudio de estructuras, conflictos y problemas sociales. El análisis del discurso se ocupa también de las relaciones entre discurso, poder, dominación y desigualdad social, y es una herramienta muy útil para los analistas políticos, pues nos permite abarcar desde lo superficial hasta lo profundo, es decir, tanto la información explícita como la implícita. Para ello emplearemos una línea de análisis diacrónico, incorporada por Foucault, cuya dirección va desde el plano fenomenal al plano generativo. 
El estudio del discurso político no debe limitarse a las propiedades estructurales del texto o el habla en sí mismo; también incluye una cuenta sistemática del contexto y sus relaciones con las estructuras discursivas (Van Dijk, 1999: p. 17).

Los temas pueden caracterizarse por ser evaluaciones polarizadas, lo cual es funcional y efectivo en el proceso político, y en la batalla por la hegemonía, apoyo y legitimidad popular. El principio estratégico general de todo discurso político e ideológico es el marco o frame (teoría desarrollada extensiva y profundamente por Lakoff), que se refiere a los encuadramientos político-ideológicos que limitan el habla y al texto político y su evaluación.

Lo más determinante en el discurso político son las estructuras y las estrategias de argumentación, en las cuales se produce la disputa política por las macroestructuras semánticas. Los significados, a su vez, reflejan los contextos políticos, cuya polarización resultará generalmente en significados contrastativos (Van Dijk, 1999: pp. 47-52).

La intensiva campaña electoral de Podemos ha pivotado en torno a tres ideas básicas: la denuncia de la casta política como un grupo cerrado y endogámico que ha convertido la corrupción en un sistema de gobierno para favorecer sus intereses; la denuncia del secuestro de la democracia por parte de esa oligarquía y la cesión de la soberanía nacional a manos de instituciones que no han sido elegidas por los ciudadanos, pero lo más importante bajo nuestro punto de vista no ha sido el qué, sino el cómo, la forma de transmitir ese discurso para que llegue a la gente y sea apoyado.

En este sentido, el andamiaje socio-político de su discurso político se asienta sobre una revisión crítica de la Transición Española y los mitos sobre los que se asienta nuestra democracia y, en nombre de la democracia misma, le hace una crítica implacable al sistema político establecido y a sus métodos, y también al sistema económico causante de los daños sociales. Es una crítica demoledora y difícil de rebatir porque, frente a un sistema que evidencia su corrupción, apela a los valores, a la moral, activando así los marcos profundos compartidos por buena parte de la población (Lakoff, 2008).

Aquí es donde se ha manifestado con mayor intensidad la noción o categoría de casta (uno de los significantes elementales de su discurso político), que lleva intrínseca una serie de acepciones negativas como linaje, privilegios, alejamiento de la gente corriente... Sin embargo, no es la palabra en sí ni su significado concreto, sino lo que su presencia en el discurso evoca en el imaginario colectivo, que es lo que Podemos pretende y consigue: trasladar al pueblo las narrativas de "la gran historia de la estafa económica, la dictadura de los mercados en contraposición con la democracia...", y concretamente, lo que logran usando esta categoría es sacar a relucir el antagonismo élites-ciudadanía, o más bien, oligarquía-pueblo. En un análisis más profundo podemos observar que ello remite a la desigualdad extrema y creciente que se vive en la mayoría de las sociedades capitalistas, donde millones de ciudadanos que subsisten con su trabajo son explotados y puestos al servicio de una minoría ínfima que acumula enormes riquezas generadas por el trabajo de los demás. 
Uno de los principales ejes del discurso de Podemos es la defensa de la soberanía popular. En este campo, el discurso público de Podemos viene usando el concepto de pueblo como referencia a la ciudadanía, pero como podemos observar tiene unas significaciones mucho más complejas y difusas. Como identidad colectiva homogénea, el pueblo es el sujeto político que ostenta normativamente la soberanía política y económica de un país, y Podemos emplea el discurso del "pueblo" en contraposición a la "casta", es decir, a las minorías de la sociedad que ostentan la hegemonía del poder político y económico. Quizás uno de sus mayores logros haya sido conseguir la hegemonía en el discurso político mediático, es decir, que el resto de fuerzas políticas se expresen ahora con la terminología que Podemos ha popularizado.

Respecto al concepto de Régimen del 78 y "crisis de régimen", la definición del actual sistema socio-político que tenemos en España como tal podría parecer una exageración retórica; sin embargo, es uno de los conceptos clave del discurso regenerador de Iglesias. Los medios de comunicación utilizan el término según sus intereses. Así, la Policía Nacional cumple con su obligación en el Estado español cuando reprime a los "violentos" de las Marchas por la Dignidad, pero si esa misma actuación se extrapola a otros casos como Venezuela o Cuba, es entonces el "Régimen" quien castiga a la oposición democrática. El término, como podemos comprobar, se utiliza de modo denigratorio y con ánimo criminalizador.

La transición española, según Pablo Iglesias, no es más que una operación en la que los sectores dominantes de la dictadura franquista cedieron una parte de su poder para no ceder en lo fundamental, y en nombre de la democracia misma, le hace una crítica elemental al sistema político establecido y a sus métodos, y también al sistema económico causante de los daños sociales. Pero también es cierto que se advierten síntomas de descomposición en ese orden, una crisis de legitimidad, dado el progresivo empobrecimiento de las mayorías sociales y la pérdida de la ya escasa calidad democrática del sistema político español.

Otro de los hilos conductores del discurso político de Podemos es el de proceso constituyente, que es, en palabras del líder de Podemos, defender que la gente tenga la palabra en todos los asuntos fundamentales para construir nuestro futuro, incluida por supuesto la elección del Jefe del Estado. Entre otros asuntos también incluye la recuperación de la soberanía económica, la puesta en marcha de un nuevo modelo productivo orientado al desarrollo económico sostenible y a la creación de empleo de calidad, pues en definitiva apelar a un proceso constituyente es invocar la idea de una revolución democrática pacífica, la realización de un nuevo contrato social en términos rousseaunianos. El constituyente, además, tiene la gran cualidad de evocar el mito fundacional, apela a lo emocional, al emotivismo como una de las bases del discurso que, a la vez, es simplificado y dirigido contundente y eficazmente al receptor.

El Proceso Constituyente, por definición, es general y amplio, con carácter deliberativo e inclusivo, y tiene como objetivo obtener una legitimidad democrática lo más amplia 
posible. Por ello, debe brindar a toda la ciudadanía las mayores opciones posibles para participar libre y democráticamente en todo el proceso, ya sea optando a candidato a la Asamblea Constituyente, influyendo en la elaboración de la nueva constitución, o ya sea participando en la ratificación definitiva del texto constitucional.

Para Podemos, y especialmente para Pablo Iglesias como comunicador político por antonomasia de la formación, son terrenos clave de la batalla ideológica los de la hegemonía, y la comunicación. El diputado y secretario general de Podemos posee un estilo de discurso educado, directo y contundente, pero bien argumentado. Adaptado a la realidad social española, y también gracias a su sólida y brillante formación académica, maneja un discurso ligero y, a la vez, completo, enlazando teoría, propuesta, critica y ejemplos o historias para facilitar la comprensión, mantener la atención del público, mostrando una total cercanía e identificación dual, y dando imagen de comodidad, de dominio del espacio y la retórica.

La candidatura liderada por Iglesias no ha logrado millones de votos solo por lo que propone, sino sobre todo por lo que critica y por la habilidad con la que lo hace, la habilidad con la que articula y emite su discurso político. Como bien señala Gómez Fernández (1995: p. 205), "la política se convierte en un campo donde la manera de hacer las cosas tiene tanta importancia como lo que se hace". Muy a menudo, la imagen provoca emociones más que facilitar informaciones.; la tranquilidad, la mesura y corrección, las buenas formas atraen y convencen más que la agresividad, molesta y repelente, y esto es paradigmático en el caso de Podemos y sus principales líderes en la comunicación de su discurso político.

\section{Construcción de la hegemonía discursiva y legitimidad a través de la escena mediática}

La hipótesis esencial del trabajo es que ambos discursos se encuadran en una lógica populista; siguiendo a Laclau, en su adaptación gramsciana a nuestra época, este modelo indica que en un contexto de crisis social, política y económica, donde proliferan demandas insatisfechas de todo tipo, el populismo sirve como lógica de articulación del discurso, como instrumento para disputar la hegemonía en las luchas políticas, y esta es la estrategia empleada por ambos líderes y movimientos en su lucha por la conquista del poder político; mediante la construcción de identidades colectivas, la importancia de los "significantes flotantes", y la construcción de la unidad popular a través de la canalización política de las demandas sociales mayoritarias, esto es, la necesidad de un "cemento social" tratan de unir los elementos heterogéneos - unidad que no está prevista por ninguna lógica articulatoria funcionalista o estructuralista- otorgando centralidad al aspecto emocional en la constitución social (Laclau, 2005: p. 10).

Esto permite hacer referencia a la psicología de las masas, cuyos estudios habían tocado algunos aspectos de crucial importancia en la construcción de identidades políticas y sociales: "La relación palabras / imágenes, el predominio de lo "emotivo" por 
sobre lo "racional", la sensación de omnipotencia, la sugestibilidad y la identificación con los líderes, etc., constituyen rasgos reales del comportamiento colectivo" (Laclau, 2005: p. 59)

La situación en que actualmente nos encontramos es una tesitura socio-política denominada por la academia como "democracia mediática", producida por el desarrollo avanzado de las nuevas tecnologías, la privatización y concentración de los medios de comunicación (en España son básicamente dos grandes corporaciones, junto con la cadena estatal) y la hegemonía absoluta de estos medios, en especial la televisión, en la vida de los ciudadanos.

Siguiendo a Muñoz-Alonso \& Rospir, (1995: p. 16), la televisión, ese medio que marca el ritmo de la actualidad, ha transformado a fondo el modo de hacer política imponiendo su dictado al proceso democrático. La política depende ahora más que nunca de los medios y, sobre todo, de la televisión. El acceso y control de los medios son en la actualidad el máximo recurso estratégico para los políticos y los partidos. Este escenario de comunicación política incorporó a los medios masivos como actor importante, lo que supone un grado de subjetividad mayor en el manejo de la información que se traduce en un mensaje.

Se genera entonces una realidad virtual mediante la información que trasmite la televisión que contribuye más que ninguna otra cosa a crear ese clima de opinión que, como dice Noelle-Neumann, rodea totalmente al individuo desde el exterior, sin que pueda escapar del todo de él. La televisión, según Sartori (1988: pp.18-19), "produce imágenes y anula conceptos, atrofiando nuestra capacidad de abstracción y entendimiento". Al igual que sucede en todas las sociedades desarrolladas, la televisión es realmente el único medio universal, en el sentido de que, en mayor o menor medida, la práctica totalidad de la sociedad tiene un contacto diario con él; En el caso de España, en 2008, sobre el total de la población mayor de 4 años, el consumo medio diario ascendió a 227 minutos, es decir 3 horas y 47 minutos, lo que, dicho en términos relativos, implica que en media los españoles dedicamos casi el 16 \% de nuestro día a ver la televisión. Aún mayor es el consumo entre la población adulta (237 minutos) y, sobre todo, en la de mayor edad: entre los mayores de 65 años el consumo medio alcanza las 5 horas y 17 minutos. El patrón de evolución reciente de ese consumo es creciente en los últimos años, desmintiendo la hipótesis ampliamente admitida de que la extensión de Internet revertiría en un consumo menor de televisión: "ella mantiene en exclusiva su condición de medio universal, es el único al que acceden a diario casi 9 de cada 10 españoles" (Wert, 2009: p. 5).

Esta fuerte tendencia está relacionada con el distanciamiento de los ciudadanos con la política por una fuerte crisis de identidades, de los partidos y posiciones ideológicas y en la aparición de estructuras autónomas de comunicación, y empresas de comunicación propietarias de varios medios. La profesionalización de la comunicación política y gubernamental reside en la necesaria adaptación a estas dinámicas, pues como podemos comprobar, de un gobierno importa más su imagen, lo que los medios dicen que hace, que lo que realmente hace. 
La información, y en el caso concreto que aquí nos ocupa, la información política, constituye el sistema nervioso de toda unidad política. No se puede olvidar que en los países democráticos la legitimidad se sustenta, sobre todo, en valores de consenso y persuasión, y en tal sentido la actividad política constituye esencialmente una forma de comunicación. Quien persigue la consecución del poder político lo hace mediante la organización de la conducta de los otros, y organización implica de modo indispensable comunicación.

Unido al necesario componente mediático, comunicativo, todo proceso de cambio político progresista pasa por constituir al pueblo como actor político colectivo. Para dominar la hegemonía, también es necesario usar el antagonismo entre el nosotros y el ellos. Ello apunta a que la descomposición de los pilares del régimen y los desanclajes de las adscripciones tradicionales pueden dar lugar a una voluntad popular nueva. La batalla política central, según Gramsci, es la ideología, y esto se traduce en una configuración del sentido común de la gente, mediante los elementos centrales que están en disputa y que Laclau identifica como significantes vacíos, que no son expresión, sino construcción. Estos significantes son portadores de legitimidad, que pueden ser abiertos o cerrados, antagonismos gigantes o identitarios de minorías. En España pueden ser, por ejemplo, la democracia, la ciudadanía, el interés general, país...

En este sentido seguimos a Gramsci respecto a que cualquier desplazamiento hegemónico debería ser concebido como un cambio en la configuración del Estado, en un sentido amplio gramsciano, como el momento ético-político de la comunidad que va a mostrar esta combinación de particularismo y universalidad inherente a la operación hegemónica. Siguiendo a Laclau (2005: pp.43-46), una relación hegemónica es aquella en la cual una determinada particularidad significa una universalidad inalcanzable. El objeto parcial se convierte él mismo en una totalidad, se convierte en el principio estructurante de toda la escena. También autores como Copjec y Deleuze se refieren a esto considerando que el objeto parcial deja de ser una parcialidad que evoca una totalidad y se convierte en el nombre de esa totalidad.

En la época en que vivimos, la sociedad es muy abierta, heterogénea, y necesita significantes que la resignifiquen continuamente. Se abre ese espacio a la resignificación mediante la fuerza performativa de la palabra. El régimen del 78 cerró muy bien esos significantes comunes mediante los consensos y el pactismo, la reconciliación..., pero actualmente las masas populares excluidas entran en la arena política y dan lugar a nuevas formas de liderazgo. En este sentido el populismo evita que la política sea mera administración, produciendo una relectura minuciosa y rigurosa de los relatos constitutivos.

Esta batalla discursiva por la hegemonía cuyo fin es la consecución del poder político y la transformación profunda de la sociedad tiene lugar en un terreno social radicalmente heterogéneo. "El discurso populista en el que se inscriben las demandas, por supuesto que va a incrementar la eficacia y coherencia de las luchas que se derivan de él. Sin embargo, las identidades (propias y del enemigo) se vuelven más difíciles de determinar" (Laclau, 
2005: p.128). Aquí aparece la necesidad de la vacuidad, de la vaguedad e imprecisión en algunos elementos fundamentales del discurso: "Esto no tiene que ver con una situación marginal o primitiva, ya que se inscriben en la naturaleza misma de la política" (ibíd.).

\section{Liderazgo, personalismo, unidad e identidad popular}

La creación de liderazgo es clave para el desarrollo político, social y económico de toda sociedad. El liderazgo es un concepto confuso, estático, simplificador; mientras que el líder participa de una visión a desarrollar en un contexto cerrado y de participación limitada, el líder político participa en el proceso como actor comprometido con asumir el reto y la responsabilidad de decidir qué es lo mejor para todos.

En cuanto a la cuestión del liderazgo, nos hallamos sobre una heterogeneidad cuya equivalencia es unida por un nombre, de lo que se deriva que necesariamente es una singularidad, y "la forma extrema de singularidad es una individualidad; la identificación de la unidad del grupo con el nombre del líder. La unificación simbólica del grupo en torno a una individualidad es inherente a la formación del pueblo" (Laclau: 2005: p.130).

La propia identidad es importante políticamente, ya que el qué decir políticamente debe ser coherente con todo ello; la clave es el contenido que determinará una posición de diferenciación y búsqueda de oportunidades en el escenario político. Tenemos que tener una visión política particular y atractiva, una simplificación interpretativa de los hechos que justifique acciones futuras que promuevan que otros sean capaces de entender y contagiarse de motivos para seguir al líder.

Para que una fuerza recién creada como Podemos, haya entrado con tanto éxito en la escena política, ha sido necesaria una estrategia de comunicación política y hegemonía mediática magistral; adaptándose a las lógicas mediáticas basadas en la audiencia, el sensacionalismo, la necesaria diferenciación... han conseguido un prestigio notable, creando expectativas en la población que los demás partidos perdieron hace tiempo.

El personalismo también es un factor determinante en nuestra cultura política. La importancia de la imagen, el carisma, la legitimidad del líder tiene, en las sociedades muy pobladas donde además las personas lidian con un ritmo de vida frenético, una base catódica, lo que implica un desplazamiento de los lugares tradicionales de poder. Los medios de comunicación son parte del proceso de construcción política, y agentes del cambio político; es lo que Blumler (en Rospir, 1995: p. 383) ha denominado el "moderno proceso público", una lucha competitiva por controlar e influir las percepciones populares de los temas y acontecimientos claves a través de los principales medios de comunicación"; esto se consigue con mayor efectividad mediante la articulación de un liderazgo comunicativo, cercano, visible y con fuerte identificación simbólica. Asistimos en el caso de Podemos a un estadio donde los políticos se presentan en la escena mediática como educadores, seductores e, incluso, como periodistas, narrando su relato con aspiración de verdad, de crítica compartida, empatía racional-afectiva y adhesión, apelando a la objetividad, la justicia y el sentido común. 
Errejón (García y Fonseca, 2015: p. 32), a quien podríamos definir como el ideólogo de cabecera de Podemos, identifica tres etapas en el proceso de problematización que lleva a la escena pública demandas compartidas de cara a articular una identidad transformadora:

1. Diagnóstico en el que definimos los problemas y los agrupamos en torno a una injusticia general.

2. Politización de la injusticia. Creamos unas identidades en pugna: culpables y víctimas.

3. Motivación para la acción en la que se argumenta la posibilidad de cambiar esa realidad.

La conclusión final es que todos terminan, de un modo u otro, aceptando el término. En términos hegemónicos -y electorales-, eso supone una batalla ganada. Integrar algunas demandas principales de otros grupos opositores supone sustraerles una de las propuestas que los dotaba de sentido.

En resumen, el primer paso para crear un discurso político consiste en identificar una serie de realidades y agruparlas en torno a conceptos más generales (significante vacío). Así, para que esas realidades formen parte de la política, hay que convertirlas en problemas políticos, con unos culpables y una posible solución colectiva articulada sobre un núcleo común.

La opción de identificar al adversario implica la integración misma a un proyecto político que forja un sentimiento de pertenencia. La cultura popular ha creado en el subconsciente colectivo una serie de asociaciones especialmente poderosas a la hora de identificar el rol de una persona en un contexto.

Por increíble que parezca, la caricaturización del rival juega un papel fundamental a la hora de crear identidades políticas. Nuevamente, Errejón en su tesis destaca la necesidad de utilizar los clichés y las generalizaciones para definir al adversario político, para que el votante visualice la historia completa. (García y Fonseca, 2015: p. 43).

Si el narrador es capaz de seleccionar aquellos personajes que tenemos en nuestro imaginario personal, conseguirá conectar de una forma más precisa con nosotros, con finalidad maniquea. La conclusión es que una buena caricaturización del adversario político debe incluir los siguientes elementos:

- Estar basada en un arquetipo existente en el imaginario colectivo

- Exagerar aspectos que causen verdadera aversión

- Crear roles compatibles con la historia que queremos contar

En resumen, supone crear las identidades políticas en función de sus antagónicos, utilizar estereotipos existentes en el imaginario colectivo para caricaturizar a tu adversario. Podemos ha sabido entender y asumir todas esas contradicciones para conseguir su objetivo último, que es construir la hegemonía discursiva, socio-política, para conquistar 
el poder político y poner en marcha un cambio profundo de nuestro sistema. Para ello ha tenido que adaptarse a las lógicas dominantes de la privatización política y mediática, mediante la humanización, simplificación y canalización de la atención, emocionalización y mayor celebridad (Holz-Bacha: 2000, p.142), así como empleando también instrumentos de persuasión social como el priming y el framing.

Los escenarios mediáticos desarrollados en las últimas décadas, las tertulias políticas (conocidas en EE. UU. como talk shows) han sido un trampolín inmejorable para dar a conocer el discurso de Podemos, pues los participantes en dichas tertulias tienen un margen mayor de tiempo y libertad para hablar de sus propuestas y críticas (en comparación con los espacios informativos o publicitarios), demostrar sus habilidades de debate, argumentativas y de réplica, y debido a la generalmente baja calidad de la discusión en estas tertulias, es accesible para politólogos con brillante formación como Iglesias, Errejón, Monedero o Bescansa, entre otros, erigirse como los referentes políticos indiscutibles, ganando credibilidad y legitimidad de forma exorbitante en el público. En su discurso también emplean muchos elementos de conexión con la ciudadanía corriente, acercándose a su lenguaje cotidiano mediante, por ejemplo, el uso de metáforas deportivas (meter goles, pisar el acelerador) con objeto de afianzar la cercanía hacia la sociedad con que interacciona.

Se trata, en primer lugar, del hecho de que generar expectativas es mucho más sugerente que presentar una realidad concreta. Ello permite crear una solución global que responda a los problemas particulares de cada colectivo. Ante eso el 'Encuadre cognitivo' es efectivo, pues conlleva la acción de encuadrar o enmarcar una nueva realidad a ese humus de premisas que ya tenemos adquiridas (García y Fonseca, 2015: p.65).

Desde Podemos convierten el voto a su causa en toda una declaración de intenciones. Ellos mismos presentan su marca, no como un partido político sino como un "instrumento" para que los ciudadanos tomen el poder. Confiar en ellos es algo más que poner un papel en una urna: es hacer historia. En este sentido, un medio que escapa del control de los grandes grupos comunicativos y de la óptica subjetiva del periodista es internet. La red de redes te permite crear tu propio medio de comunicación con el que llegar directamente a tu elector. De esta forma, el partido o institución puede controlar directamente el mensaje, Esto no solo lo coloca en una posición ventajosa sino que, además, le marca la agenda al medio. No se trata de lanzar una medida concreta, sino de explicar todo el relato político que la envuelve (García y Fonseca, 2015: p.121). El cambio de mentalidad que esto supone en la estrategia de marketing, se basa en que no hay que pensar como un anunciante sino como un medio de comunicación, pues es desde ahí donde se construyen la percepción que tenemos de la realidad

Respecto a \#Podemos en Twitter, al igual que \#Podemos25M, hay que resaltar su fulgurante progresión en tan poco tiempo, logrando llegar a más de 400.000 seguidores en Twitter (duplicó y más sus seguidores tras el éxito electoral). Pablo Iglesias también ha logrado colocarse como el segundo político con mayor número de seguidores en Twitter 
(482.000 seguidores) solo superado por el presidente del gobierno, Mariano Rajoy (510.000 seguidores).

En Facebook el dominio del partido es aún mucho mayor; Podemos logró en poco tiempo un caladero de 662.000 usuarios que han manifestado su simpatía por el partido, seguido de lejos por PP (69.672) y PSOE (64.611). En Youtube, por su parte, parece dar una lección de contenido interesante para los usuarios de Internet en su canal que, a pesar de nutrirse con 200 vídeos menos que la media del resto de formaciones para las elecciones europeas (subió 112 vídeos), consigue superar los 2,6 millones de visualizaciones, es decir, casi las mismas que la suma de todos los vídeos del resto de partidos. De media, cada vídeo de Podemos fue visto 23.400 veces, evidenciando que ha dado con la clave de lo que realmente interesa al ciudadano sin necesidad de hacer spam audiovisual.

\section{Conclusiones y retos futuros de la investigación}

La irrupción de Podemos y de su líder Pablo Iglesias en el escenario político español es la consecuencia de multitud de factores, uno de los cuales es, sin duda, la fructífera y larga campaña electoral televisiva desde la que Iglesias empezó a convertirse en el fenómeno social que es hoy. Su relación con la pequeña pantalla no es un hecho fortuito, sino que es intencionado y estratégico; en sus palabras, "trabajamos en experimentar en la comunicación política desde el principal espacio de socialización política que es la televisión". Para ello aprovechan una de las pocas grietas que a priori tiene el sistema en el que vivimos, y la lógica mercantil, la lógica del beneficio, de las audiencias, por las cuales los promotores de Podemos han tenido tanta presencia en tertulias políticas televisivas como LaSexta noche, Las mañanas de Cuatro, El gato al agua... etc.

La sensibilidad emocional, pasional, el componente sentimental y hasta romántico que evocan es uno de los fundamentales en la construcción de una amplia identidad popular transformadora. Los comunicadores del discurso político de Podemos dan una imagen de gente muy preparada, formada, pero aun así corriente, normal, sencilla, lo cual incide en la identificación popular.

La repercusión social de Podemos, e inherentemente de su líder, especialmente en Internet y redes sociales, está pulverizando las propias expectativas. La clave del éxito de la comunicación de Podemos ha sido saber colarse en el salón de casa y en los ordenadores de los españoles, a través de la reiteradas apariciones de su líder en televisión, y en los ordenadores, a través de una muy activa y acertada campaña en Facebook y Twitter.

En síntesis, el discurso de Podemos y de su líder Pablo Iglesias ha tenido un rápido crecimiento y calado en todos los frentes que se plantearon, una expansión vertiginosa tanto en las redes sociales y de comunicación, como en las urnas, en las calles, en las reuniones, las plazas, los círculos..., lo que se traduce en una creciente y progresiva presencia de Podemos en la vida pública de nuestro país. A este respecto cabe afirmar que una práctica se convierte en hegemónica cuando logra subvertir las prácticas opositoras que compiten con ella por la articulación de lo social. Cuanto más abierto es lo social, más 
espacio encuentra la dimensión hegemónica. Así, se define a la hegemonía como aquel intento de extender un conjunto relativamente unificado de discursos, como el horizonte dominante de lo social.

El reciente éxito de Podemos tiene mucho que ver con la constante aparición mediática de sus líderes y exponentes, sobre todo Pablo Iglesias. Él, junto con el "Grupo de Somosaguas" se dieron cuenta de que esa es la única forma (o al menos la más eficaz) de poder disputar el sentido común hegemónico a los poderes dominantes, y, con ello, hacer llegar su discurso a la gente común, al pueblo trabajador. Tenían claro, entre otras cosas, que había que abordar la lucha por la hegemonía en los lugares políticos televisivos, tanto al nivel de crear nuevos espacios donde poder realizar tertulias en las cuales poder hacer presente el discurso político transformador en los medios del capital. "Si no se está en la esfera pública en la que pelean los medios de comunicación, no existes", decía Iglesias allá por 2012, añadiendo que "si eso implica asumir contradicciones, habrá que asumirlas, y el que no quiera asumirlas, que no haga política".

El hecho de que ahora Podemos tenga tanta presencia en las televisiones del capital, así como la presencia de Pablo Iglesias en las mismas durante estos últimos tiempos, no es fruto de la nada, o de un favor concedido por los dueños de los grandes medios de comunicación, sino que es el resultado de un trabajo bien hecho, de una estrategia política perfectamente pensada, de un esfuerzo constante y, por supuesto, de un talento que han sabido explotar de forma efectiva a la vista de los resultados.

A raíz de sus capacidades comunicativas, mucha gente empezó a conocerlo y a estar con él y sus opiniones; a seguirlo en los medios y a confiar en él como persona que defiende sus mismos intereses, o, cuanto menos, que comparten sus ideas frente a las ideas de aquellos con los que se enfrenta en los debates. Tener luego la valentía de querer convertir eso en una fuerza política de masas, asumiendo los grandes riesgos y costos de presentarte a unas elecciones y a la postre obtener unos resultados impresionantes sorprenden a todo el mundo y hacen que su discurso y su éxito electoral pasen a ser el tema central del debate político durante meses, así como ocupar portadas (y ataques) en todos los principales diarios, radios y televisión del Estado; máxime cuando a día de hoy las encuestas lo sitúan ya como segunda fuerza política del Estado y la propia población empieza a contemplarlo como única alternativa al bipartidismo.

La principal clave de este torbellino social mediático y político es convertir al ciudadano en protagonista y no a la inversa, como normalmente hace el resto de los partidos, que conciben las redes sociales como un instrumento eminentemente unidireccional. Podemos, en cambio, no solo es más constante y participativo en redes como Twitter, Facebook o YouTube, sino que abre el abanico de espacios de comunicación -y no de discurso unidireccional- con la ciudadanía.

Las herramientas del marketing político son realmente efectivas en la búsqueda de modificar el comportamiento electoral, que exige dos fases consecutivas: notoriedad y adhesión. Podemos ha logrado en la figura de sus principales líderes, mediante la ex- 
posición mediática de su discurso contundente, simplificado y sustantivo, conseguir la adhesión racional y emocional de millones de personas. Actualmente la mediatización de la política exige del mensaje político una adecuación específica considerando que los medios actúan como caja de resonancia de la comunicación política, pero despolitizando los temas; una de las claves del discurso populista es saber encajar el mensaje político en el sentido común hegemónico, como un elemento importante más en la cotidianeidad de la sociedad.

Es importante aclarar tres conceptos:

1) El marketing como modo de crear el discurso, centrado en la necesidad de satisfacer las demandas de los votantes. El discurso es el modo de organizar la percepción que tenemos de la realidad.

2) En cuanto a la hegemonía cultural, una clase dominante no solo basa su poder en el aparato represor, sino también en la imposición de unos valores y una visión al resto de la comunidad. 27

3) Podemos es hoy el partido político que mejor ha sabido resumir la realidad en una serie de preguntas que solo ellos pueden responder. En términos discursivos, ahora mismo tienen una ventaja competitiva que no es sino la antesala de la hegemonía.

A modo de conclusión, estos dos discursos políticos vienen generando en España estas tres características narrativamente consecutivas:

1. Gran aceptación social de su discurso político; triunfo del populismo.

2. Auge expansivo y rápido en un contexto de extrema necesidad.

3. Ruptura del sistema de partidos y revolución política: Hacia una radicalización de la democracia.

Finalmente destacamos que ante la importancia tremenda de los medios de comunicación, el alcance y profundad de la democracia de los medios, Podemos ha construido un discurso sólido consistente y con gran aceptación social, y ha utilizado las herramientas más poderosas actualmente en la política para amenazar el régimen establecido. Queda por conocer y estudiar cómo afronta Podemos las grandes expectativas que ha generado su discurso político en este año electoral que tenemos por delante.

\section{Bibliografía:}

Del Río, E. (2015). ¿Es "populista" Podemos? Página Abierta, 236. Recuperado de: http://www. pensamientocritico.org/eugrio0115.htm

García, A. E Fonseca Porras, E. A. (2015). El método Podemos. Marketing marxista para partidos no marxistas. Madrid: Última Línea.

García Luengo, O. (2005). Desafectos y medios de comunicación: el estado de la cuestión de una relación difusa. Panorama, Reflexión política, año 7, n. ${ }^{\circ}$ 14. Bogotá: IEP (UNAB). 
Gómez Fernández, P. (1995). El marketing político: más allá de la publicidad y las encuestas, en MuñozAlonso, A. E Rospir, J. I. (1995). Comunicación Política. Madrid: Editorial Universitas

Gramsci, A. (1975). Cuadernos de la cárcel. México D. F.: Editorial ERA.

Holz Bacha, C. (2003). Comunicación política: entre la privatización y la espectacularización. Buenos Aires: Diálogo Político. N. ${ }^{\circ} 1$.

Laclau, E. (2005). La razón populista. Buenos Aires: Fondo de Cultura Económica.

Müller, J. (2014). \#PODEMOS. Deconstruyendo a Pablo Iglesias. Barcelona: Deusto.

Muñoz-Alonso, A. E Rospir, J. I. (1995). Comunicación política. Madrid: Editorial Universitas

Sartori, G. (1988). Teoría de la democracia. Madrid: Alianza.

Van Dijk T. E Rodrigo Mendizábal, I. (1999). Análisis del discurso social y político. Quito: Abya-Yala.

Wert, J. I. (2009). Los medios en España: materiales para un debate. Madrid: Fundación Ciudadanía y Valores. 